\title{
Teacher readiness in applying ATL skills in the International Baccalaureate Middle Years Programme Schools
}

\author{
Roziah Ramli, Mohd Isha Awang, Nurahimah Mohd Yusoff \\ School of Education, Universiti Utara Malaysia, Malaysia
}

\begin{tabular}{l} 
Article Info \\
\hline Article history: \\
Received Jan 30, 2021 \\
Revised Aug 26, 2021 \\
Accepted Sep 11, 2021 \\
\hline Keywords: \\
Approaches to learning skills \\
Case study \\
Lesson study \\
Teacher readiness
\end{tabular}

\begin{abstract}
This article aims to understand the challenges faced by teachers in implementing the Approaches to Learning Skills (ATL Skills) for the teaching of Bahasa Melayu (Malay Language) in the International Baccalaureate Middle Years Programme Schools (MYPIB) in Malaysia. This qualitative case study employed purposive sampling that involved six resilient teachers who were directly involved in the implementations of ATL Skills consisting of four Bahasa Melayu teachers, a MYPIB coordinator and ATL skills coordinator. Triangulation was used to compare data from different sources using semi-structured interviews, story completion tasks, and document analysis. Using the ATLAS.ti software as an aiding tool, thematic analysis was carried out to identify the themes that emerged from the codes. Findings showed that teacher readiness is a challenge that needs to be addressed in the process of applying ATL skills in the MYPIB implemented by the Malaysian Ministry of Education. Teachers still need courses and training to improve their mastery in the ATL skills application. This study provided implications to teaching and learning, and recommendations to teachers as well as the Ministry to make improvements in the effort to apply ATL skills in the teaching-learning processes at the MYPIB schools.
\end{abstract}

This is an open access article under the CC BY-SA license.

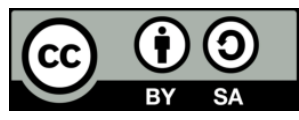

Corresponding Author:

Roziah Ramli

School of Education

Universiti Utara Malaysia

06010 Sintok, Kedah, Malaysia

Email: roziahramli2021@gmail.com

\section{INTRODUCTION}

The International Baccalaureate (IB) or The International Baccalaureate Organization (IBO) is headquartered in Geneva, Switzerland. The IBO is an independent organization that is not a government body [1], [2]. There are four educational programmes offered by IB, namely Diploma Programme (DP), International Baccalaureate Middle Years Programme (MYPIB) for secondary school students, Primary Year Programme (PYP) for primary school students, and also IB Career-related Certificate [3]-[5]. However, this study only focuses on the MYPIB programme in tandem with the implementation of this programme under the PPPM 2013-2025 [5]. Developed in 1994, MYPIB is now growing rapidly with a total of 77849 candidates from 819 MYPIB schools in 98 countries around the world have sat for the MYPIB examination in 2019 [6]. Figure 1 shows the number of MYPIB schools by region worldwide. The map shows the statistics of the candidates who sat for the MYPIB certificate qualification examination in 2019 (Data sources were obtained and adapted from the IB Middle Years Programme. Final Statistical Bulletin May 2019). 


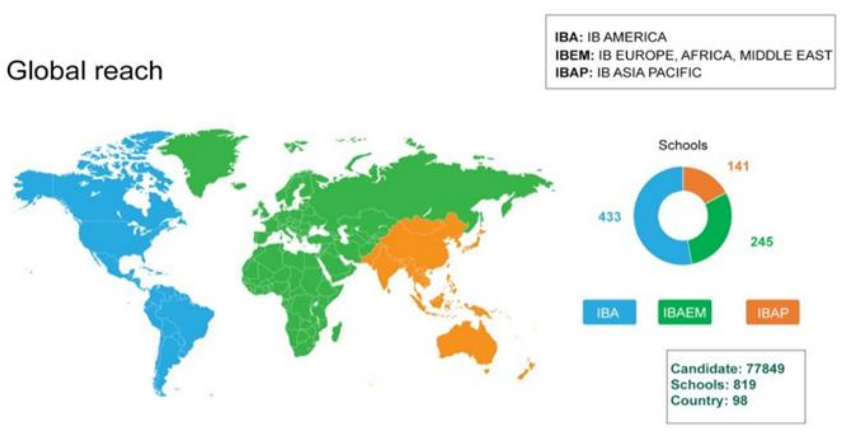

1B Midcllo Years Programme Final Statistical Bulletin May 2019

Figure 1. The number of MYPIB schools by region worldwide

In achieving 'social change' aspiration and intensifying global competition, the Ministry of Education Malaysia (MOE) implemented a major change to Malaysia educational system through a comprehensive transformation programme which will take place in three waves from 2015 to 2025 [7], [8], aiming to provide international standard education that will bring about a positive impact in improving academic quality and producing international-minded students [9]. In this regard, MOE has introduced the International Baccalaureate Middle Years Programme (MYPIB) in selected MOE schools starting in 2015 [5]. MYPIB was introduced under initiative 20: Cultivating Higher Order Thinking Skills (HOTS) as an effort to provide students with relevant knowledge, skills, and values to face the challenges of the $21 \mathrm{st}$ century and to raise the standard of national education to the international level [1], [2]. However, there are still very few studies on MYPIB conducted in Malaysia.

In Malaysia, the MYPIB schools are using the MYPIB framework which is developed for students between the ages of 11 to 16 years [3], [4] and adapted to the secondary school students in Malaysia which are between the ages of 13 to 17 years. These MOE MYPIB schools are still using the Malaysian curriculum and students are required to sit for the Malaysian Certificate of Education (Sijil Pelajaran Malaysia) and it is compulsory for them pass the Bahasa Melayu (Malay Language) paper [1], [5]. However, MOE MYPIB schools are to comply with the guidelines and rules set by the IBO [10]. Among the rules are the application of Approaches To Learning (ATL) skills in teaching [4], [7] even though Malaysia teachers are still lacking in training and exposures to the ATL skills.

These ATL skills are related to the development of thinking skills, strategies, and attitudes as well as the ability to reflect on self-learning. ATL skills are divided into five categories, namely communication skills (CS), social skills (SS), thinking skills (TS), research skills (RS), and self-management skills (SMS). The MYPIB extends ATL skills categories into 10 developmentally appropriate clusters that students need to master [4]-[6]. Through the application of ATL skills, students develop curriculum-related skills that help them to learn how to learn. ATL skills can be learned and taught, improved with practice, and developed in stages. Mastery of ATL skills provides a solid foundation for learning individually and with others. ATL skills help students prepare themselves and demonstrate learning through meaningful learning. In conclusion, ATL skills focus on the learning process, helping students to be confident, independent, and able to manage themselves for life. Figure 2 shows the description of the five ATL skills which detailed the ten clusters.

Teachers are seen as key drivers of a programme or planning and teachers act as agents of change in education [7], [8]. This is further strengthened by previous study [10], which states that in order to understand a process of programme implementation or education policy, a researcher must investigate and explore the elements of understanding of the implementers.

The main concern of the application of ATL skills is that teachers are still not ready to implement transformation in education [11]. This is based on the lack of understanding of teachers on the process of applying ATL skills to the point of causing confusion and lack of confidence of teachers when teaching ATL skills [12], [13]. Teachers' understanding of the concept of applying ATL skills needs to be studied for any misconception will later hamper the implementation of the ATL skills as the MYPIB has only been implemented for five years in Malaysia.

Thus, this study aims to understand the issues and challenges faced by teachers in the process of applying ATL skills in MYPIB MOE schools and provide reports and recommendations to teachers and the Ministry of Education Malaysia as to make improvements in the application of ATL skills in the teaching and learning process. 


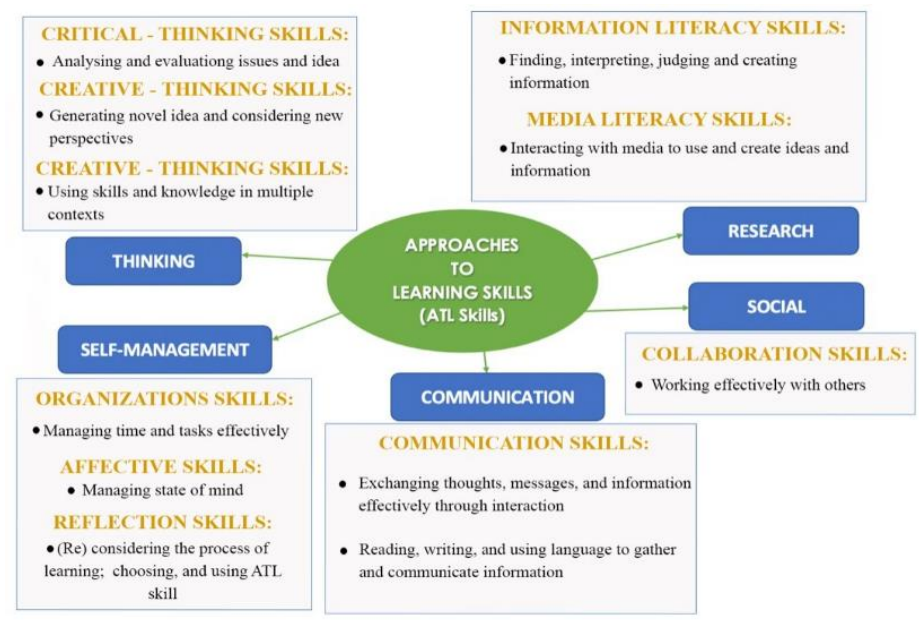

Figure 2. Ten ATL skills cluster framework

\section{RESEARCH METHOD}

In line with the objectives of this research which aims to understand, the researchers use a qualitative design in the form of a case study [14], [15] to answer this main research question: What are the issues and challenges faced by teachers in the process of applying ATL skills during teaching?

A case study design is chosen as it allows researchers to understand the real situation which occurs in the process of implementation of ATL skills in teaching Language and Literature (Bahasa Melayu) in two of the MYPIB schools under the Ministry of Education. These two schools are the first MYPIB cohort that produced the first batch of students after five years of the MYPIB implementation.

A case study also allows the participants to convey information in more depth [16]. Researchers use a variety of data collection techniques such as completing stories, semi-structured interviews and document analysis to obtain rich data [14] in producing a detailed description of the ATL skills application process.

\subsection{Sampling}

Purposive sampling [17] is used in this research where the participants chosen are teachers who are directly involved in the process of applying ATL skills either through the teaching or administrative process, as they are able to provide detailed and in-depth information to researchers. Six teachers were selected as participants in the study. Four of them are Bahasa Melayu teachers, while the fifth and sixth teachers were selected based on their importance in the ATL skills implementation with one appointed as the coordinator MYPIB and the other is the ATL coordinating skills. In addition, both participants are responsible for developing and coordinating the application of ATL skills in MYPIB schools. The selection of these two administrative teachers is in line with the research requirements as proposed by Forrest [13]. In order to comply with the study procedure, the researchers have obtained permission from the schools' principals and consent from the teachers involved in this study. This is important as qualitative research requires participants to give high commitment in the process of repeated data collection and requires researchers to engage with participants for a relatively long period of time [18].

\subsection{Instrumentation and trustworthiness of the study}

Before the actual study was conducted, a pilot study was carried out to test the interview protocol to two Bahasa Melayu teachers from an MYPIB school. They were then not selected as the participants in the actual study again. Document analysis was also performed with reference to the verification report by IB World School. As a result, after consulting with several experts, the researchers made improvements to the actual research data collection method. Among the improvements made by the researchers was the addition of the story completion task. The method was selected due to the uneasiness felt by participants who were uncomfortable in answering the questions related to the issues and challenges they are facing, as both are related to their job commitment and their dissatisfaction with certain parties. Thus, changes were made by first having the participants to complete a story, in order to create comfort as well as to reduce the uneasiness of the participant in the actual data collection process. Moreover, this method was suitable in building trust between the participants and the researchers [14]. To prove the reliability of this study, three methods of data collection were used as data triangulation [19], namely story completion task, semi- 
structured interview, and document analysis. All interview transcripts were reviewed by the participants to ensure the validity of the content and to avoid misunderstandings and biases of researchers. The profiles of the six participants are listed in Table 1. Pseudo names were used to maintain the confidentiality and identity of participants [19].

Table 1. Profile of the participants

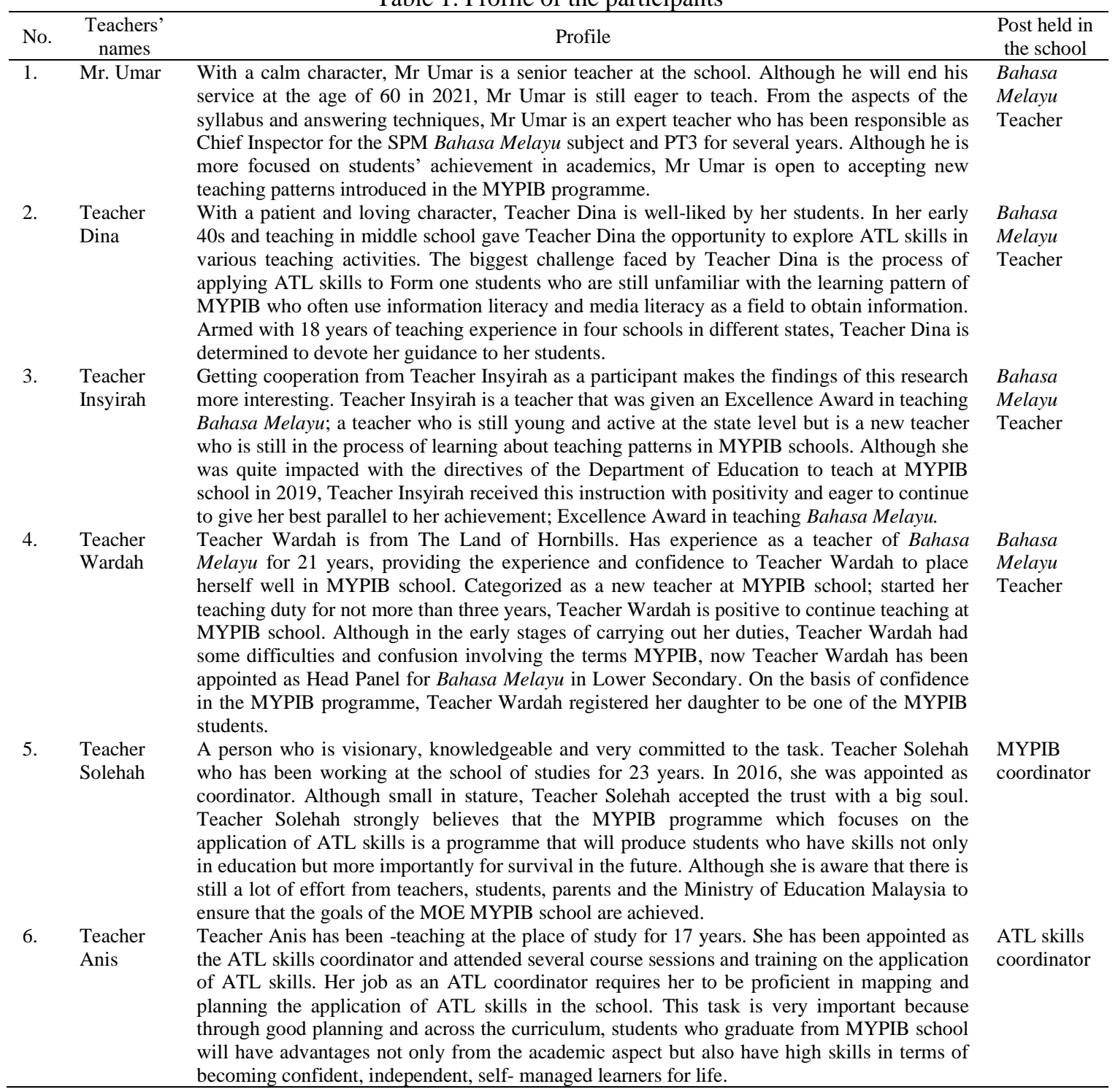

\subsection{Data analysis}

In this study, ATLAS.ti software was used to analyze the data and determine the themes. ATLAS.ti software is increasingly being accepted as computer-aided qualitative data analysis software (CADQA). Furthermore, ATLAS.ti is more relevant to the nature of this study because of its ability to provide better thematic analysis [20].

\section{RESULTS AND DISCUSSION}

Several themes emerged based on the research question, "What are the issues and challenges faced by teachers in the process of applying ATL skills during teaching?" Before obtaining the main theme, the researchers repeatedly read the transcript as well as construct the code to identify the main theme [21]. After going through a rigorous and repeated process in encoding, analyzing, and performing data validation from experts [14], the following themes and subthemes emerged. 


\subsection{Issues and challenges related to teachers' readiness during the process of applying ATL skills in teaching}

After conducting a thorough analysis of the interview data, story completion task, and document analysis, issues and challenges related to teachers' readiness are the main theme that needs immediate attention to ensure the effectiveness of the ATL skills implementation. Among the subthemes that arise from this issue are teachers' understanding of the teaching of ATL skills application, teachers' appointment, courses, and training requirement, language, and technological constraints.

\subsubsection{Teachers' understanding of the ATL skills implementation in teaching}

Teachers' understanding is found to be limited and the teaching process or application of ATL skills still needs improvement. The following is the data from a report containing comments related to teachers made during the verification process by IB World School in 2017.

"The updated action plan has more detailed information, but the knowledge of this information within the school community is limited." (Documentation: MYP authorization 30/10/2017).

"Teachers had difficulty giving examples of how they have adapted teaching to build on what students know and can do." (Documentation: MYP authorization 30/10/2017).

This issue is supported by an interview data with the teachers showing that teachers do not really understand the teaching concept of MYPIB, especially the application of ATL skills. The following are data that refers to teachers' understanding.

"The first-time verification was made; the school did not succeed in getting accreditation because at that time the teachers did not understand much. We do not get enough exposure, we also do not know, do not understand IB style." (Interviewed: Teacher Solehah).

"At the initial stage I felt a bit stressed because it was difficult to understand the real concept of the application of ATL. Can I continue to teach here?" (Story completion: Teacher Anis).

\subsubsection{Aspects of staffing}

The issue of teachers' readiness that involves teachers' appointments such as the transfer of experienced teachers as well as the placement of new teachers is also a major challenge to the ATL skills application process. The data of teachers' interviews with new teachers are as:

"At first I did not understand much, especially the terms." (Interview: Teacher Wardah).

"As a teacher who received Excellence Award, my friends and JPN officers have sparked me a challenge to teach at one of the MYPIB schools. I accepted the challenge, of course at first I was traumatized and depressed." (Interview: Teacher Insyirah).

When interviewed by experienced teachers on this teachers' appointment issue, Teacher Solehah as the MYPIB coordinator and Teacher Anis as the ATL skills coordinator commented on this issue and challenge.

"Problems continue when experienced teachers who are competent in the ATL skills implementation are transferred due to promotions or other reasons and new teachers without the knowledge in ATL are placed or posted to this school." (Interview: Teacher Anis).

"Yes, we also have problems with new teachers. As new teachers, they have to start from the basics while having to continue doing things that have already started and they do not have the knowledge about ATL. These new teachers need time to develop themselves to the needs of MYPIB from the existing teachers in the school. Nonetheless, to assist new teachers with basic knowledge of MYPIB is such a constraint and not the same as the knowledge we get from $M Y P I B$ itself because the amount of time required for a teacher to master the skills of applying ATL skills is very long." (Interview: Teacher Solehah).

\subsubsection{Requirements for courses and training}

Data from the 2019 verification documentation shows the need for courses and training provided to teachers: 
"The governing body should review the school budget to ensure that all identified costs related to the implementation of the MYP are included, especially for the teacher PD for the training of teachers in significant areas in the MYP like IDU, ATL and Inquiry based teaching and learning." (Documentation: MYP Authorization 14/06/2019).

"I have never gotten the opportunity to take a course with MYPIB myself even though I have served since 2015. As a teacher, I really need this course. It was the Head of Panel who went for the course. But now he has been transferred, promoted." (Interview: Teacher Dina).

"Yes, the challenge is about the training obtained by teachers to apply these ATL skills. Teachers also get less exposure on the application of ATL skills from MYPIB itself either directly or indirectly. The training given by IB before are only on the basic level. Teachers were only given exposure on the ATL's category and ATL's cluster. Then for each subject, teachers only refer to the guidelines provided by the IB. Looking at this, usually the teachers in IB schools, under the Ministry of Education Malaysia, we gained those skills by trying... if we want to master it, we have to try it ourselves." (Interview: Teacher Solehah).

\subsubsection{English constraints}

Language is the main medium in the delivery of information. Since MYPIB is an international education programme, the medium of information delivery including the programme framework is English. Teachers may have met the proficiency level in English, but for Bahasa Melayu teachers who mostly use the Malay language, is quite difficult for them in obtaining detailed information about this MYPIB programme (ATL skills). These constraints have been stated in the following interviews:

\footnotetext{
"When we attended workshops or meetings conducted by MYPIB, there are language constraints as English is fully used." (Interview: Mr Umar).

"Yes, the challenge in terms of language. Had to refer to the English teacher to better understand." (Interview: Teacher Dina).

"In the beginning, it was a challenge in understanding terms; when the terms were mentioned, I still did not understand those terms. Until now, there are still some terms that are still confusing." (Interview: Teacher Wardah).
}

\subsubsection{Constraints on technology mastery}

Another issue involving teachers' readiness is the constraint of technological mastery especially for senior teachers. The following interview data is an expression of the teachers' feelings.

"For me it may be an age factor, so sometimes I'm quite slow to understand something, especially related to IT and online stuffs, when most of the information and grading uses IT." (Interview: Teacher Anis).

"I am getting older and the increasing changes in the use of the Internet are a challenge for me because I am not good in the use of the Internet. Looking for teaching materials online, keying in data, those will hinder my work." (Interview: Mr Umar).

\section{IMPLICATION}

Based on the data obtained, the main theme that needs to be discussed related to issues and challenges in the process of applying ATL skills in Malaysia MYPIB schools is teachers' readiness. Research involving the theme of teacher readiness needs to be given attention because teachers are the driving force of any programme or plan. Research on the importance of teacher-related research acting as agents of change in education has also been discussed in previous studies [22], [23]

Another interesting finding is that teachers desperately need regular courses and training [24], [25] to equip them with an understanding and mastery of the ATL skills application process which in turn can enhance their professionalism as teachers in MYPIB schools. Based on the in-depth analysis on the theme of teachers' readiness, five subthemes have been identified as challenges to the application of ATL skills namely teachers' understanding of the application of ATL skills, teachers' appointment, requirements for courses and training, English language constraints and technological mastery constraints. To achieve the MOE aspirations in the implementation of MYPIB schools, steps need to be taken to overcome each of these challenges.

Three of these challenges, namely: teachers' understanding, English language constraints and technological mastery constraints are related to teacher professionalism should be improved by the teachers themselves. On teacher comprehension, the major weakness in schools is the lacking of understanding [26]. 
As educators in international standard schools, teachers should be able to improve themselves by acquiring professional knowledge [27]. In other words, they must always find a way to enrich themselves with knowledge of ATL skills and practice them before the application is done during the teaching process.

\section{RECOMMENDATION}

Teachers need to equip themselves with teaching and learning trends that can be adapted to the process of applying ATL skills and content. Teachers need to be aware that times are changing and teaching also needs to change following the current situations that make technology such as information literacy, social literacy, and communication literacy are closely related to ATL skills. Along with that, teachers need to improve their mastery of technology as discussed in this recent study [28], [29], because the study found that teaching style has an impact on students' academic performance [30].

In terms of English proficiency, although the teachers who participated in the study teach Bahasa Melayu subject, the teachers need to improve their mastery of the second language especially English as almost all sources for MYPIB information are available in English. In facing this issue, teachers should not be left alone to face these challenges. School administrators are advised to implement professional development programmes in a planned and periodic manner. The recommendation submitted to improve the understanding and quality of teachers' teaching is through the practice of Lesson Study module which is one of the approaches to improve the professional development of teachers in the teaching and learning process through the professional learning community (PLC). The implementation of the Lesson Study module that was first introduced in Japan is expected to change the individualized teaching approach of teachers in the form of sharing, discussion and cooperation through community learning. Generally, there are four steps introduced in the implementation of lesson study, namely identifying problems and goals; planning lessons; implementing lessons; and making reflections [31]. In addition, through PLC, teachers can improve English proficiency [32], as well as information technology-related skills [33].

\section{CONCLUSION}

The application of ATL skills introduced in MYPIB programme aims to produce students who have effective learning skills and are skilled to manage life in the future. However, based on the study, the issue of teacher readiness which includes teachers' understanding of the application of ATL skills, teachers' appointment, requirements for courses and training, English language constraints, and technological knowledge constraints are the main challenges in the process of applying ATL skills in MOE MYPIB schools. Therefore, we would like to recommend that the MOE pay great attention to the professional development programme for teachers as the main pillars of programme implementers. In fact, we also suggest that the officers responsible for monitoring the implementation of this programme at the Ministry and Jabatan Pendaftaran Negara (JPN) level responsible for the planning and development of this programme to participate in all professional development programmes so that the administrators have the same understanding, knowledge, and goals to strengthen the MYPIB programme.

\section{ACKNOWLEDGEMENTS}

The authors would like to thank all teachers in the MYPIB schools and the Ministry of Education Malaysia. The authors also would like to thank the Scholarship Division at Ministry of Education Malaysia for granting the scholarship.

\section{REFERENCES}

[1] Ministry of Education Malaysia, Laporan Tahunan 2017: Pelan Pembangunan Pendidikan Malaysia 2013-2025. Ministry of Education Malaysia. Federal Government Administrative Centre, 2018.

[2] N. Selamat, et al., "Kajian penilaian Middle Years International Baccalaureate Programme (MYPIB) tahun 2018," Jurnal Penyelidikan Pendidikan, vol. 20, pp. 1-11, 2019.

[3] C. Hughes, "A critical analysis of the International Baccalaureate's Middle Years Programme assessment design with particular focus on feedback," J. Res. Int. Educ., vol. 13, no. 3, pp. 203-217, 2014, doi: $10.1177 / 1475240914550783$.

[4] E. Wright, M. Lee, H. Tang, and G. Chak Pong Tsui, "Why offer the International Baccalaureate Middle Years Programme? A comparison between schools in Asia-Pacific and other regions," J. Res. Int. Educ., vol. 15, no. 1, pp. 3-17, 2016, doi: 10.1177/1475240916635896.

[5] Ministry of Education Malaysia, Pelan Hala Tuju Pendidikan Bahasa Melayu 2016-2025. Putrajaya: Bahagian Perancangan dan Penyelidikan Dasar Pendidikan, 2018. 
[6] K. Park, V. Caine, and R. Wimmer, "The Experiences of Advanced Placement and International Baccalaureate Diploma Program Participants: A Systematic Review of Qualitative Research," J. Adv. Acad., vol. 25, no. 2, pp. 129-153, 2014, doi: 10.1177/1932202X14532258.

[7] International Baccalaureate Organization, Middle Years Programme (MYP): From principles into practice. International Baccalaureate Organization (UK) Ltd. Peterson House, United Kingdom, 2014.

[8] N. Li, Approaches to Learning: Literature Review. International Baccalaureate Organization, 2012.

[9] R. A. Razza, A. Martin, and J. Brooks-Gunn, "Are Approaches to Learning in Kindergarten Associated with Academic and Social Competence Similarly?" Child Youth Care Forum, vol. 44, no. 6, pp. 757-776, 2015, doi: 10.1007/s10566-015-9307-0.

[10] M. Fullan and G. Scott, New Pedagogies for Deep Learning Whitepaper: Education PLUS. Collaborative Impact SPC, Seattle, Washington. Pieejams, 2014.

[11] A. Dickson, L. B. Perry, and S. Ledger, "Letting Go of the Middle Years Programme: Three Schools' Rationales for Discontinuing an International Baccalaureate Program," J. Adv. Acad., vol. 31, no. 1, pp. 35-60, 2020, doi: $10.1177 / 1932202 X 19869006$.

[12] M. Condoleon, "Talk The TOK and Walk The WOK: How International Baccalaureate subject teachers integrate Theory of Knowledge in their teaching," Master Thesis, University of Sydney, 2019.

[13] S. Forrest, "Can CPD enhance student-centred teaching and encourage explicit instruction of International Baccalaureate Approaches to Learning skills? A qualitative formative assessment and summative evaluation of an IB school's in-house CPD programme," J. Res. Int. Educ., vol. 17, no. 3, pp. 262-285, 2018, doi: $10.1177 / 1475240918816401$.

[14] V. Clarke and V. Braun, "Some very important starting information," in Successful Qualitative Research. A Practical Guide for Beginners. SAGE Publications Ltd, 2013.

[15] R. K. Yin, Case study research and applications: Design and methods, 6th ed. SAGE Publications, 2018.

[16] C. R. Boddy, "Sample size for qualitative research," Qual. Mark. Res., vol. 19, no. 4, pp. 426-432, 2016, doi: 10.1108/QMR-06-2016-0053.

[17] J. W. Creswell and D. Cresswell, Research design: Qualitative, quantitative, and mixed methods approaches. SAGE Publications, 2018.

[18] J. W. Cresswell, "Qualitative Procedures," in Research design: Qualitative, quantitative, and mixed methods approaches, SAGE Publications, 2008.

[19] L. Cohen, L. Manion, and K. Morrison, Research methods in education, 8th ed. New York: Routledge, 2018.

[20] T. M. Paulus and J. N. Lester, "ATLAS.ti for conversation and discourse analysis studies," Int. J. Soc. Res. Methodol., vol. 19, no. 4, pp. 405-428, 2016, doi: 10.1080/13645579.2015.1021949.

[21] V. Braun and V. Clarke, "One size fits all? What counts as quality practice in (reflexive) thematic analysis?" Qual. Res. Psychol., vol. 18, no. 3, pp. 328-352, 2020, doi: 10.1080/14780887.2020.1769238.

[22] M. N. A. Aziz, N. M. Yusoff, and M. F. M. Yaakob, "Challenges in using authentic assessment in 21st century ESL classrooms," International Journal of Evaluation and Research in Education (IJERE), vol. 9, no. 3, pp. 759768, 2020, doi: 10.11591/ijere.v9i3.20546.

[23] A. S. Bustamante, L. J. White, and D. B. Greenfield, "Approaches to learning and science education in Head Start: Examining bidirectionality,” Early Child. Res. Q., vol. 44, pp. 34-42, 2018, doi: 10.1016/j.ecresq.2018.02.013.

[24] M. Z. Haron, M. M. M. Zalli, M. K. Othman, and M. I. Awang, "School's facilities and achievement of students in ulul albab model Tahfiz schools in Malaysia: A mediating roles of satisfaction," Int. J. Sci. Technol. Res., vol. 9, no. 2, pp. 3026-3030, 2020.

[25] R. Ramli and M. Y. Nurahimah, "Self-efficacy and differentiated instruction: A study among Malaysian school teachers," Univers. J. Educ. Res., vol. 8, no. 4, pp. 1252-1260, 2020, doi: 10.13189/ujer.2020.080416.

[26] I. Maryani and S. T. Martaningsih, "Correlation between Teacher's PCK (Pedagogical Content Knowledge) and Student's Motivation in Primary School in Indonesia," International Journal of Evaluation and Research in Education (IJERE), vol. 4, no. 1, pp. 38-44, 2015.

[27] A. Kusumaningtyas and E. Setyawati, "Teacher Performance of the State Vocational High School Teachers in Surabaya," International Journal of Evaluation and Research in Education (IJERE), vol. 4, no. 2, pp. 76-83, 2015.

[28] K. Drossel, B. Eickelmann, and M. Vennemann, "Schools overcoming the digital divide: in depth analyses towards organizational resilience in the computer and information literacy domain," Large-Scale Assessments Educ., vol. 8, no. 1, 2020, doi: 10.1186/s40536-020-00087-w.

[29] E. Istiningsih, Suyatno, and Widodo, "Academic supervision to improve teachers' readiness in utilizing information and communication technology in vocational high schools," Univers. J. Educ. Res., vol. 8, no. 10, pp. 4365-4373, 2020, doi: 10.13189/ujer.2020.081002.

[30] N. D. S. Chetty, L. Handayani, N. A. Sahabudin, Z. Ali, N. Hamzah, and S. Kasim "Learning styles and teaching styles determine students' academic performances," International Journal of Evaluation and Research in Education (IJERE), vol. 8, no. 4, pp. 610-615, 2019, doi: 10.11591/ijere.v8i4. 20345.

[31] C. Lewis and J. Hurd, Lesson Study Step by Step: How Teacher Learning Communities Improve Instruction. Portsmouth: New Hampshire Heinemann, 2011.

[32] X. Cheng and X. Pan, "English language teacher learning in professional learning communities: a case study of a Chinese secondary school," Professional Development in Education, vol. 45, no. 4, pp. 698-712, 2019, doi: 10.1080/19415257.2019.1579109.

[33] L. Skultety, G. González, and G. Vargas, "Using Technology to Support Teachers' Lesson Modifications during Lesson Study,” J. Technol. Teach. Educ., vol. 25, no. 2, pp. 185-213, 2017. 